\title{
Ignored aspect of Personal Life in Work-Life Integration
}

\author{
J.R.Vaishnavi Prasad \\ Lecturer, Krupanidhi School of Management
}

\begin{abstract}
Work and life are two sides of human existence and striking a balance between them has always been a challenge to all of us. With the invasion of technology into our personal space, possibility of working remotely was considered a boon initially. However, the burdens of official work being carried back home started taking a toll on personal health and social relationships. Many organizations address work-life integration from the perspective of official work and family life. An individual's life comprises of personal, family and social life. Friends at work place and social media to a certain extent meet employees' social demands whereas personal life interests are usually ignored. This research attempts to study the different components of work-life balance and explore their impacts on individuals. It has been found that while generation X succumb to work pressure or quit to do something personally gratifying, generation $Y$ millennials follow a clearly laid out career and personal interest plan. They have little time for family and therefore avoid long term relationships and responsibilities. Work-life balance which was once considered a smart strategy has turned into a threat to the survival of mankind in the long run. Alderfer's ERG theory is related to various work-life components in this study. The article also provides suggestions to employees, organizations and policy makers to avoid adverse effects of work-life balance.
\end{abstract}

Keywords:work-life, personal interest, generation $Y, E R G$ Theory

\section{Introduction}

Achieving a balance between work and life is the goal of most of the people in today's interconnected world. When it was found that perfect work-life balance cannot happen, the shift to work-life integration where official tasks were incorporated into one's life routine beyond office hours occurred. A lot has been explored in the context of work-life integration. Most often, work-life integration referred to official work and family life. While work denotes officetasks related to on-record job, the term 'life' connotes family life, social life and personal life.

According to World Health Organization (WHO),health constitutes not only physical but also mental and social well-being. Thus, 'life' in work-life balance includes personal, social and family well-being. Sadly, organizations ignore the personal and social life of an employee. Work-life balance was addressed from a person's ability to meet work demands and immediate family demands. Social life of an employee has been taken care of through official get-togethers and casual team outings to a certain extent. Personal life refers to physical, mental fitness as well as special interests. Insurance policies and wellness programs of organizations address the first two components but fail to recognize the third important aspect of special interests of a person. This causes a vacuum or helplessness in employees in their middle age. Popularly called the mid-life crisis, there exists a higher probability of individuals unable to balance their personal selves undergoing this phase. To avoid such situations, present working population of millennials belonging to generation $\mathrm{Y}$ has serious apprehensions of family and social life. They are particular about personal health and hobbies. These people donot mind compromising on their family life or even social life for privacy.As they are fine-tuned to stretchable work hours and the need to relax through personal interests, additional responsibilities are not welcome. Most of them are not ready to get into marital relationship or start a family fearing commitments.It's high time we considered work-life integration as a threat to survival of mankind in the long run.

\section{Literature Review}

Various studies and researches conducted around work-life balance tend to concentrate on gender perspectives, industry-specific views and different countries' take on it. Little has been researched on the impact of different components of work-life balance on present workforce. An article (Kossek, Lewis, \& Hammer, 2009) published in Human Relations Journal laments on the lack of core employment changes to support worklife balance. Most organizational initiatives attempt to support only the needy employee on a temporary basis without structural and cultural changes in the organization. A recent research by REID, E., \& RAMARAJAN (2016) in Harvard Business Review identified three types of employee strategies in coping with work-life balance and their impact on organizational performance. Accepters are the ideal workers obliging to the management. While passers try managing work and life in a smart way, revealers simply deny after office hour calls. CASTELLANO's (2013) article discusses about the negative effects of flexible work hourssuch as lesser 
performance rating and slower career progression for employees opting them. Currie and Eveline's research(2011)on technology's role in impacting work-life balance mentions terms such as 'work extensification', 'work intensification' and 'intrusion and invasion into homes'. In the Indian context, it has been observedin a research article (Bharathi \& Padma Mala, 2016)that personal factors highly impact work-life balance of women working in the IT industry. A research article published by DESHMUKH \& DESHMUKH (2016) throws light on work pressure of female employees in educational institutes. Professional challenges and enhancers did little to them. A recent report by International Labour Organization published in The Hindu (2017) mentioned that employees working remotely witnessed higher work-life interference through long work hours, intense pressure and insomnia. On the contrary, research conducted in Oman (Agha, Azmi, \& Irfan, 2017)emphasizes the importance of work-life integration for higher levels of satisfaction.

The following are the objectives of the study:

- To understand the various components of work and life in work-life balance

- To explore the effects of lack of importance to 'life' in work-life balance among generation X and generation Y employees

- To suggest better work-life balance techniques for individuals, organizations and policy makers

\section{Research Methodology}

This study attempts to understand the subsets of work-life balance, explain the impact of ignored components of 'life' on an individual and suggest possible mitigation efforts. Therefore, it is partly descriptive and partly exploratory in nature. The insights gained by the author are results of formal and informal discussion with various individuals over a period of time in addition to literature reviews. The conceptual framework arrived at by comparing Alderfer's ERG Theory with work-life balance components is a primary finding. Thus, it can be concluded that secondary as well as primary data are used.

\section{Work-Life Balance to Work-Life Integration}

Elizabeth Hatfield (2016) borrows Cowan and Hoffman's definition of work-life balance for her book, as an attempt to achieve a state of equilibrium in the temporal, emotional, psychological demands of work and personal life. In other words, work-life balance is an act of effectively managing time and effort towards career aspirations and personal fulfillment. In the traditional era, work and personal life were viewed as two different compartments where the former was responsible in enhancing the latter. Slowly, the influences of work and life spilled over each other and their boundaries blurred (Major \& Burke, 2013). The need to integrate work and life was understood by organizations and individuals alike. Therefore, when Corporates expected employees to be available 24/7, assistance to employees to manage life was attempted to be met through facilities such as gym, day care, entertainment room, bank and even supermarket within the office premises. Employees on the other hand, did not mind taking work back home.

However, the long term effects of such work-life integration have come to light only recently. Strain, role conflicts and relationship issues were early signs of negative work-life balance. Present day millennials are well aware of career demands and need for personal space. They have well-defined professional aspirations as well as personal interest goals such as music, photography, fitness etc. Due to these already established goals, there seems to be no time for family. Generation $\mathrm{Y}$ is wary of getting into a relationship on a long term basis. They donot want any other responsibility. This mindset will not only affect individual contentment or organizational effectiveness, but also human kind over the years.

\section{Components of Work-Life}

Work and life have different connotations to different people. While work predominantly refers to job tasks that offer remuneration or career growth prospects, life has many subsets. Job tasks indicate direct on-thejob activities and assigned responsibilities. Learning and development programmes, skill upgradation and jobrelated knowledge enhancing tasks are covered under career progression.

Components of life can be classified into personal and social well-being. Organizations usually refer to the social component of 'life', particularly immediate family responsibilities, whenever work-life balance is considered. Flexitime, telecommuting, maternity/paternity leave benefit, childcare, medical insurance for dependents and family get-togethers proposed by organizations to integrate work-life substantiates the previous claim. Although family is supposed to be an individual's first social circle, the importance of belongingness to peer group or friends circle cannot be undermined. To a certain extent, organizations fulfill these needs through team work and training programs. Also, social media such as Facebook and WhatsApp helps individuals stay connected virtually with their people. One significant aspect which is severely affected in work-life integration is personal well-being which includes physical and mental health. 


\section{Components of Work-Life Balance}
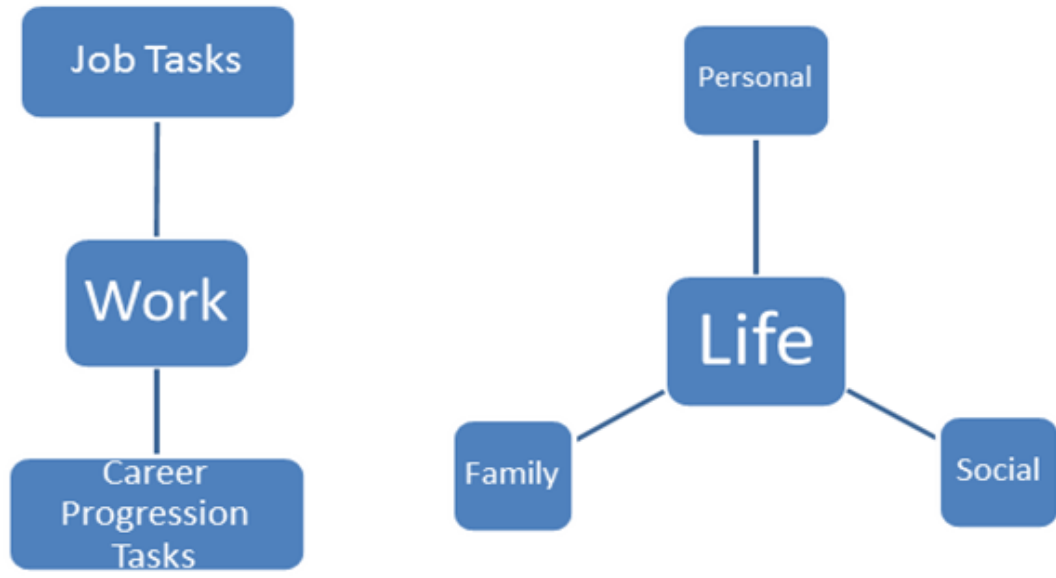

Figure 1. Source: Primary (2017)

VII. Ignored Aspect of 'Life'

Little care is given to an individual's physical and emotional health. In spite of spacious office campuses and state-of-the-art gym facilities made available to employees, organizations fail to recognize the need to give their human resources private time to relax and rejuvenate themselves. Every individual may possess a unique interest out of office which he/she may want to pursue but is unable to do so for various reasons. It may range from anything as simple as reading a book to as ambitious as reaching to the top of Mt.Kilimanjaro! An individual's monotonous over-packed routine drains him/her of his energy and enthusiasm. The individual's inability to pursue interests reflects in decreased performance levels. As indicated in Alderfer's ERG Theory, existence (work and physical well-being, in this case), relatedness (family and social well-being) and growth (career aspirations and personal interests) motivate employees across levels at different points of time(Griffin \& Moorhead, 2013).

Unlike ERG Theory where individuals if frustrated in attaining higher order needs return to lower order needs, current human capital donot hesitate to completely denounce the bare minimum need satisfiable by the job i.e. existence, to fend for themselves. Mid-life crisis is a result of such frustration where employees feel dissatisfied with their work. They may either quit to starting something that excites them or diverting attention towards means of achieving inner peace through spirituality or other modes. Millennials on the other hand, prefer work-life balance over financial security concerns as they believe in 'living in the present'. And 'life' according to millennials refers to personal freedom. Therefore, they are wary of committing themselves for higher responsibilities. Although friends and peers compensate for family life in their early days, life seems lonely in the long run. This threatens the very existence of human kind.

Comparison between Alderfer's ERG Theory and Work-Life Balance Components

\begin{tabular}{|cc|}
\hline Growth & $\begin{array}{c}\text { P Personal interests } \\
\bullet \text { Career aspirations }\end{array}$ \\
\hline Relatedness & $\begin{array}{c}\bullet \text { Family } \\
\text { Existence }\end{array}$ \\
\hline
\end{tabular}

Figure 2. Source: Primary (2017) 
The major findings of the study are as follows:

\section{Findings}

- Work refers to job related tasks and career progression tasks while life encompasses personal, family and social well-being.

- Alderfer's ERG Theory can be compared with work-life balance components. Physical well-being and work can be classified under existence needs, social well-being and family under relatedness needs and career aspirations and personal interests under growth needs.

- Coping mechanisms of work-life balance is different for generation X and generation Y. Generation X succumb to work pressure or quit the job to divert attention towards entrepreneurship, spiritual or other similar goals. Generation Y, suspecting such mid-life crisis, simply avoid taking family responsibilities owing to already-established career and personal goals.

\section{Suggestions for Work-Personal Life Balance}

Concerns surrounding work-life balance or integration have been spelt for quite some time. Solutions seem to be the challenge. Following are some of the suggestions to strike work-life balance:

\section{For employees:}

- While a clear distinction between life and work timings is near to impossible in today's fast-paced globalized world, certain self-imposed restrictions can be of help. For instance, important/urgent principle in time management matrix can be followed.

- An assertive approach to deny additional responsibilities outside work can be adopted. Accommoding requests whenever possible and politely refusing whenever not possible may be viewed favorably by the management.

- As life component has various subsets, individuals must diligently pay attention to their well-being, family responsibilities as well as personal interests as appropriate. Paying too much attention or too little attention to one or more of these components will have long-term adverse implications.

\section{For organizations:}

- Human resource is a complex but important contributor towards organizational effectiveness. Ignoring the human aspect of this resource by attempting to extract maximum benefit is akin to killing the duck that lays golden eggs.

- There is no substitute for home, no matter how comfortable an organization tries to make the work place. Thus, it's important to respect an individual's need for private time out of office.

- Family is just one aspect of work-life balance. Compensations, fringe benefits and facilities to make good for the employees' loss of presence in his/her individual life moments will have severe ill-effects in the long run.

For policy makers:

- Protecting the interests of employees through stringent rules and policies is the duty of the government and other regulating agencies. Framework for employee work-life balance can be formulated after consulting experts and professional bodies.

- A full-fledged act to regulate business organizations with regard to working hours, flexible pay component for over-time and result-based evaluation rather than process-based evaluation must be put in place.

\section{Conclusion}

Work-life balance which was once considered a smart strategy for managing varied interests is posing serious threats to humanity. It can be in the form of physical strain, emotional stress or social seclusion. Whatever is the result, it is high time individuals, organizations and policy makers started rethinking on integrating two or more diverse components of work-life.

\section{References}

[1]. AFP. (2017, February 16). U.N. study says working remotely can lead to more stress, insomnia. The Hindu.

[2]. Agha, Azmi, \& Irfan. (2017). Work-Life Balance and Job satisfaction: An Empirical Study Focussing on Higher Education Teachers inOman. International Journal of Social Science and Humanity, 164-171.

[3]. Bharathi, S. V., \& Padma Mala, E. (2016). A Study on the Determinants of Work-Life Balance of Women Employees in Information Technology Companies in India. Global Business Review, 665-683.

[4]. CASTELLANO, S. (2013). The Dilemma of Workplace Flexibility. T+D, 67(12).

[5]. Currie, J., \& Eveline, J. (2011). E-technology and work/life balance for academics with young children. Higher Education, 533-550. 
[6]. DESHMUKH, S., \& DESHMUKH, P. (2016). IMPROVING HR INTERVENTIONS RELATED TO WORK LIFE BALANCE FOR EDUCATIONAL SECTOR . INTERCONTINENTAL JOURNAL OF HUMAN RESOURCE RESEARCH REVIEW, 165176.

[7]. Griffin, R. W., \& Moorhead, G. (2013). Organizational Behavior: Managing People and Organizations. New York: Cengage Learning.

[8]. Hatfield, E. F. (2016). Communication and the Work-Life Balancing Act: Intersections across Identities, Genders, and Cultures. Lanham: Lexington Books.

[9]. Kossek, E. E., Lewis, S., \& Hammer, L. B. (2009). Work—life initiatives and organizational change: Overcoming mixed messages to move from the margin to the mainstream . Human Relations, 3-19.

[10]. Major, D. A., \& Burke, R. J. (2013). Handbook of Work_Life Integration Among Professionals: Challenges and Opportunities. Northampton: Edward Elgar Publishing.

[11]. REID, E. \&. (2016). MANAGING THE HIGH INTENSITY WORKPLACE. Harvard Business Review, 84-90. 